\title{
Is prophylactic laser peripheral iridotomy for primary angle closure suspects a risk factor for cataract progression? The Chennai Eye Disease Incidence Study
}

\author{
Lingam Vijaya, ${ }^{1}$ Rashima Asokan, ${ }^{1,2,3}$ Manish Panday, ${ }^{1}$ Ronnie George ${ }^{1}$
}

'Glaucoma Project, Vision Research Foundation, Sankara Nethralaya, Chennai, Tamil Nadu, India

${ }^{2}$ Elite School of Optometry, Chennai, Tamil Nadu, India ${ }^{3}$ Birla Institute of Technology and Science, Pilani, Rajasthan, India

\section{Correspondence to} Dr Lingam Vijaya, Medical Research Foundation, Sankara Nethralaya, 18, College Road, Chennai, Tamil Nadu 600006 , India; cgscedis@gmail.com

LV and RG contributed equally.

Received 20 March 2016 Revised 16 June 2016 Accepted 11 July 2016 Published Online First 2 August 2016

CrossMark

To cite: Vijaya L,

Asokan $\mathrm{R}$, Panday $\mathrm{M}$, et al. Br J Ophthalmol

2017;101:665-670.

\begin{abstract}
Background To report the risk of cataract progression among primary angle closure suspects (PACS) 6 years after they underwent laser peripheral iridotomy (LPI).

Methods In the Chennai Eye Disease Incidence Study, 6 years after their baseline evaluation, 4421 subjects were examined again. As part of a detailed evaluation cataract was graded using the Lens Opacities

Classification System II; progression was defined as change of cataract by two or more grades or history of cataract surgery in the 6-year period. Only bilaterally phakic subjects with less than N2 or C2 or P2 cataract at baseline with no history of any form of glaucoma, primary angle closure and pseudoexfoliation were included.
\end{abstract}

Results There were 3205 eligible subjects. Of these, 190 had undergone LPI for PACS. In comparison to the study population, they were significantly older $(p<0.001)$, female $(p=0.008)$, urban residents $(p=0.001)$ and patients with hypertension $(p<0.001)$.

During the intervening period, 53 subjects had undergone cataract surgery. The cataract progression rate was significantly greater (OR $1.7,95 \% \mathrm{Cl} 1.3$ to 2.4 , $\mathrm{p}<0.001)$ in those who had undergone LPI. For the study population the baseline risk factors for progression of cataract were age $(p<0.001)$, female gender $(p=0.01)$, diabetes $(p<0.001)$ and LPI $(p<0.001)$. Diabetes and female gender were significant risk factors for nuclear and cortical cataract progression; LPI was a risk factor only for cortical cataract (OR 1.6, 95\% Cl 1.1 to $2.3, \mathrm{p}=0.007$ ).

Conclusions There was significant cataract progression in 6 years following LPI for PACS.

Primary angle closure glaucoma (PACG) is a major cause for blindness worldwide. ${ }^{1}{ }^{2}$ Population based studies have been instrumental in highlighting that a large proportion of the elderly population in Asia will be having asymptomatic primary angle closure suspect (PACS). ${ }^{1-5}$ Some of them progress to primary angle closure (PAC) or PACG. ${ }^{67}$ Laser peripheral iridotomy (LPI) is the first line of treatment and it is known to eliminate the pupillary block mechanism in eyes with angle closure. Even though LPI is considered to be safe, there are reports of side effects such as visual symptoms, corneal endothelial changes and cataract progression. ${ }^{8-10}$ While there is broad consensus that LPI is indicated for PAC or PACG the need for LPI for PACS is debateable. ${ }^{11}$ Till the debate gets resolved with more robust data, one may have to look at the risk versus benefit of LPI for PACS in decision-making. Gathering knowledge about the possible side effects of LPI helps in appropriate decision-making for people with PACS. In this study we report the risk of cataract progression objectively, using changes in the Lens Opacity Classification System II (LOCS II) grading, 6 years following LPI for PACS, from a large population based study.

\section{METHODS}

The Chennai Glaucoma Study was designed to estimate the prevalence of glaucoma. ${ }^{12}$ A sample size of 4758 was arrived at assuming an $85 \%$ response rate for an assumed 3\% population prevalence of glaucoma with a relative precision of $25 \%$ and a design effect of 2. Four thousand eight hundred subjects, each from the rural and urban populations, were enumerated. Trained social workers performed the enumeration by carrying out a door-to-door survey. During enumeration, demographic information was collected. All eligible subjects were allotted a unique nine-digit identification number and were invited to come to the base hospital for detailed ophthalmic examination. The study was conducted between 2001 and 2004 . From the enumerated cohort of 9600, 7774 (rural: urban-3924:3850) subjects participated in the study. Six years later (2007 and 2010), this cohort was examined again to determine the incidence and progression of the eye diseases-the Chennai Eye Disease Incidence Study. Participants from the baseline cohort were enumerated again by social workers and invited to undergo a detailed ocular examination at the base hospital. In case of refusals, the social worker made up to three household visits on different days to request them to come for the examination. In spite of this if they did not respond they were considered non-participants. The study was performed in accordance with the tenets of the Declaration of Helsinki after obtaining written informed consent. The examination protocols were similar for both the studies. The institutional review board approved the study.

\section{Clinical examination}

All participants underwent a detailed ophthalmic examination at a dedicated study facility at the base hospital. A detailed history was elicited pertaining to medical and ophthalmic problems. The eye examination consisted of measuring best-corrected visual acuity using logarithm of minimum angle of 
Figure 1 Study population flow chart.

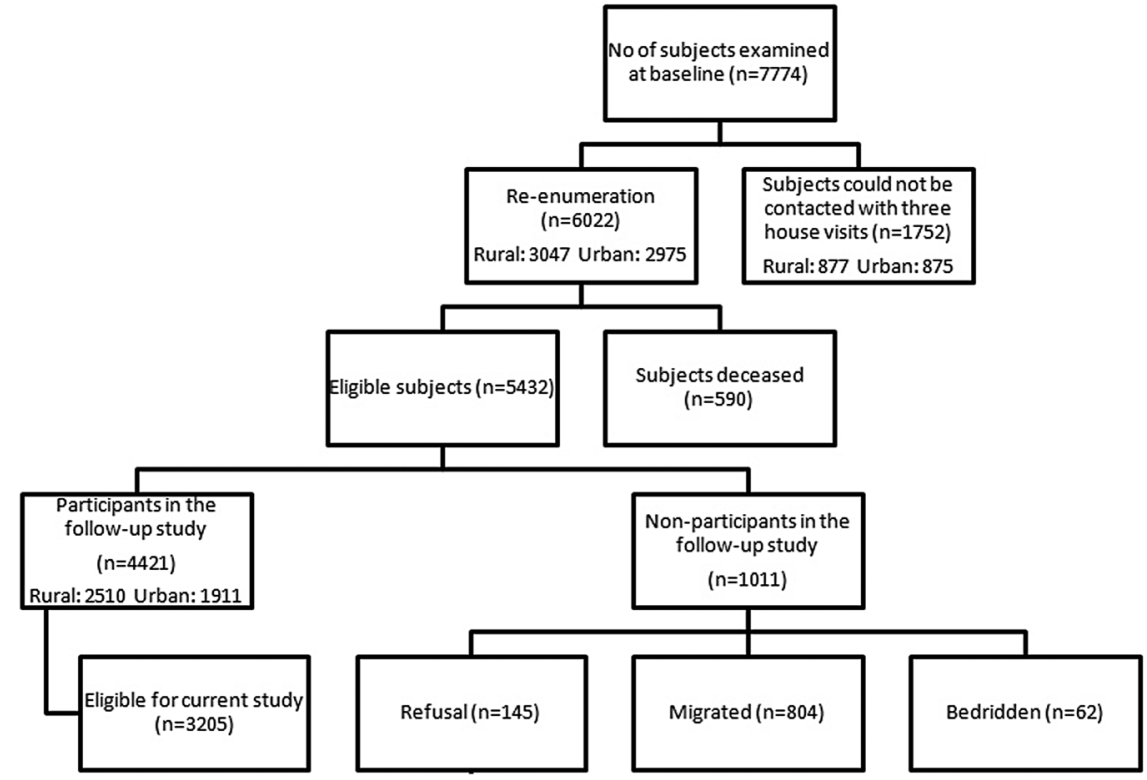

resolution 4-m charts (Light House Low Vision Products, New York, USA), slit lamp biomicroscopy, intraocular pressure (IOP) measurements using a Goldmann applanation tonometer (Zeiss AT 030 Applanation Tonometer, Carl Zeiss, Jena, Germany), gonioscopy (including indentation gonioscopy for narrow angles) using a four-mirror Sussman lens (Volk Optical, Mentor, Ohio, USA), grading of lens opacification at the slit lamp using LOCS II with minimum pupillary dilatation of $6 \mathrm{~mm}$, detailed retinal examination with a binocular indirect ophthalmoscope using a +20-dioptre lens and stereoscopic evaluation of the optic nerve head using a +78 dioptre lens at the slit lamp. In brief, the grading of lens opacities by LOCS II was done with the slit beam that was set at the narrowest setting, at $45^{\circ}$ to the visual axis at a height just overlapping the pupil and the beam was focused to the centre of nucleus. Retro illumination with the maximal red reflex was obtained keeping the illumination centred in or around the pupil. Lens opacities were compared with a standard set of photographs that was mounted and retro illuminated on a light box. According to photographic standards, the lens was graded in five grades of nuclear cataract (N0, NI, NII, NIII, NIV), five grades of posterior subcapsular cataract (PSC; P0, PI, PII, PIII, PIV) and seven grades of cortical cataract (C0, Ctr, CI, CII, CIII, CIV, CV) according to increasing severity. Experienced study ophthalmologists assessed all gradings. For the current study, we included only bilaterally phakic subjects with less than N2 or C2 or P2 cataract at baseline, and excluded subjects with any form of glaucoma, PAC and pseudoexfoliation.

\section{Diagnostic definitions}

The definitions of PAC disease were based on definitions suggested by the International Society of Geographical and Epidemiologic Ophthalmology (ISGEO) classification with a difference in the extent of closure required for disease classification. ${ }^{13}$ PACS: an eye in which the posterior trabecular meshwork was not seen for $>180^{\circ}$ on gonioscopy; PAC: an eye with PACS and peripheral anterior synechiae and/or elevated IOP without glaucomatous damage of the optic disc; PACG: PACS with evidence of glaucoma as defined by ISGEO.

Table 1 Baseline characteristics of the study population

\begin{tabular}{|c|c|c|c|}
\hline Parameter studied & $\begin{array}{l}\text { Subjects without PACS } \\
(\mathrm{N}=3015)\end{array}$ & $\begin{array}{l}\text { Subjects with LPI for PACS } \\
(\mathrm{N}=190)\end{array}$ & $p$ Value \\
\hline \multicolumn{4}{|l|}{ Age (years) } \\
\hline $40-49$ & 1690 & 69 & \multirow[t]{4}{*}{$<0.001$} \\
\hline $50-59$ & 861 & 74 & \\
\hline $60-69$ & 384 & 37 & \\
\hline$>70$ & 80 & 10 & \\
\hline Male:female & 1348:1667 & $66: 124$ & 0.008 \\
\hline Rural:urban & 1683:1332 & $81: 109$ & 0.001 \\
\hline Literate:illiterate & 1096:1919 & $65: 125$ & 0.58 \\
\hline Occupation & & & \\
\hline Manual:non-manual & 1074:1941 & $61: 129$ & 0.35 \\
\hline $\begin{array}{l}\text { Hypertension } \\
\text { (No:yes) }\end{array}$ & 1841:1174 & $90: 100$ & $<0.001$ \\
\hline $\begin{array}{l}\text { Diabetes mellitus } \\
\text { (No:yes) }\end{array}$ & $2630: 385$ & $159: 31$ & 0.18 \\
\hline
\end{tabular}




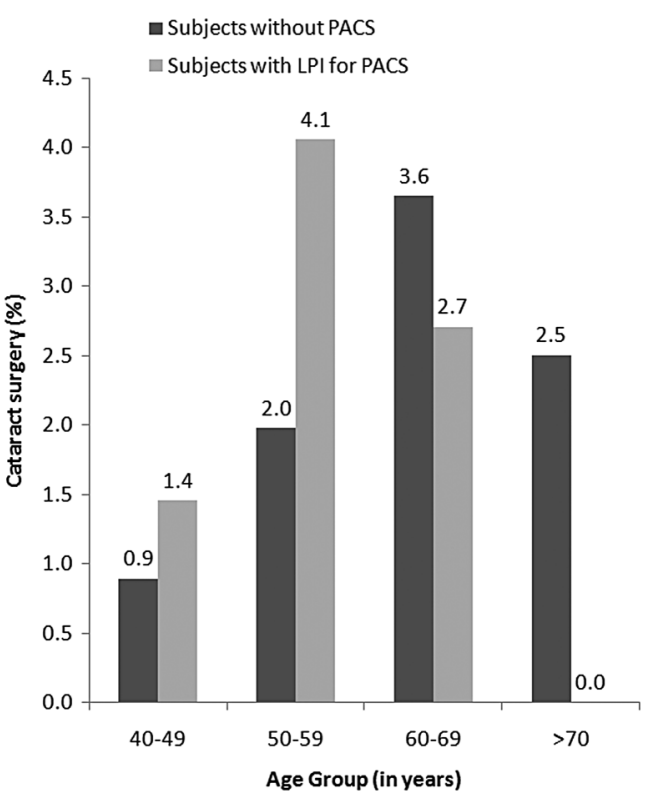

Figure 2 Cataract surgery rates in the study population among the different age groups. PACS, primary angle closure suspect; LPI, laser peripheral iridotomy.

Cataract progression was defined as change of cataract grade by two or more grades on LOCS II parameter or a history of cataract surgery in the interval between baseline evaluation and follow-up. A cataract too advanced to grade was also considered as a change in LOCS. Diabetes mellitus and systemic hypertension were defined based on current use of antidiabetic or systemic antihypertensive medication, respectively. Body mass index (BMI) was defined as weight in kilograms divided by the square of height in metres $\left(\mathrm{kg} / \mathrm{m}^{2}\right)$. BMI categories were grouped as underweight $\left(<18.5 \mathrm{~kg} / \mathrm{m}^{2}\right)$, normal $\left(18.5-25 \mathrm{~kg} / \mathrm{m}^{2}\right)$, overweight $\left(>25 \mathrm{~kg} / \mathrm{m}^{2}\right)$ and obese $\left(\geq 30.0 \mathrm{~kg} / \mathrm{m}^{2}\right)$.

\section{STATISTICAL ANALYSIS}

Statistical analysis was performed using SPSS V.15. Subjects were classified into four groups based on age at baseline-4049 years, 50-59 years, 60-69 years, and 70 years and above.
Subjects Without PACS

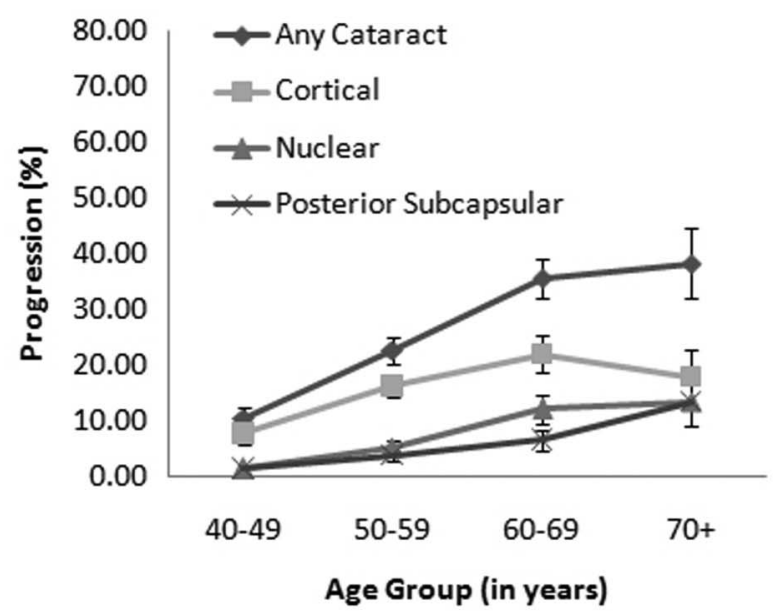

\section{Subjects with LPI for PACS}

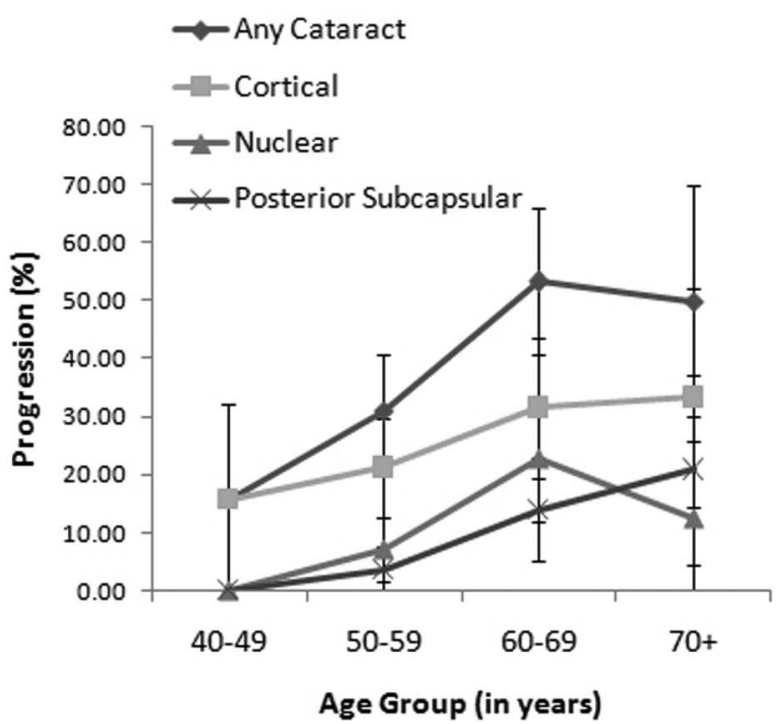

Figure 3 Progression of cataract in the study population among the different age groups. (Error bars represent $95 \%$ Cls.) PACS, primary angle closure suspect; LPI , laser peripheral iridotomy.

Table 2 Cataract status in the study population after 6 years

\begin{tabular}{lll}
\hline Parameter studied & Subjects without PACS & Subjects with LPI for PACS \\
\hline Age (years) (N=3205) & & \\
$\quad 40-49$ & 895 & 19 \\
$50-59$ & 1234 & 87 \\
$60-69$ & 654 & 60 \\
$>70$ & 232 & 24 \\
Nuclear cataract progression & $2781: 186$ & $163: 22$ \\
(No:yes) (N=3152) & $2520: 447$ & $138: 47$ \\
$\begin{array}{l}\text { Cortical cataract progression } \\
\text { (No:yes) (N=3152) }\end{array}$ & $169: 16$ \\
PSC cataract progression & $2836: 131$ & $116: 74$ \\
(No:yes) (N=3152) & $2318: 697$ &
\end{tabular}


Parameters were assessed for normality, and comparison of variables between subjects with and without LPI for PACS was done using t-test for continuous variables and $\chi^{2}$ test for categorical variables. Risk factors for progression of cataract were assessed using generalised estimating equation logistic regression incorporating age, gender, location of residence, LPI, BMI, occupation, literacy, smoking, smokeless tobacco use, alcohol consumption, diabetes mellitus and hypertension. Statistical significance was assessed at $\mathrm{p}<0.05$ and ORs are presented with 95\% CI.

\section{RESULTS}

Of the 7774 subjects examined at baseline, we could not contact 1752 subjects (rural: urban 877:875) since they migrated with no forwarding address. Of the 6022 subjects (rural: urban 3047:2975) who could be contacted/information was available, 590 persons were deceased. There were 5432 eligible subjects in the incidence cohort of which 4421 (rural: urban 2510:1911) responded and were examined again. The reasons for the nonparticipation included-refusal $(145,2.7 \%)$, migration (804, $14.8 \%)$ and being bedridden $(62,1.1 \%)$, (figure 1). The reproducibility of lens grading showed good agreement between study ophthalmologists (weighted $\kappa>0.80$ ).

At 6 years, the participants who met our criteria for analysis were 3205; out of this, 190 had undergone LPI for PACS at the baseline visit. The baseline characteristics of the study population are given in table 1 . Subjects in the study group of LPI for

Table 3 Baseline risk factors for cataract progression in the study population

\begin{tabular}{|c|c|c|c|}
\hline \multirow[b]{2}{*}{ Baseline risk factors* } & \multicolumn{3}{|c|}{ Progression of cataract } \\
\hline & No of subjects & $\begin{array}{l}\text { Adjusted } \\
\text { OR }(95 \% \mathrm{Cl})\end{array}$ & p Value \\
\hline \multicolumn{4}{|l|}{ Age (years) } \\
\hline $40-49$ & 1759 & 1.00 & \\
\hline $50-59$ & 935 & 2.2 (1.9 to 2.7$)$ & $<0.001$ \\
\hline $60-69$ & 421 & 3.5 (2.7 to 4.4$)$ & $<0.001$ \\
\hline $70+$ & 90 & 3.7 (2.4 to 5.7$)$ & $<0.001$ \\
\hline \multicolumn{4}{|l|}{ Gender } \\
\hline Male & 1414 & 1.00 & \\
\hline Female & 1791 & 1.3 (1.1 to 1.5$)$ & 0.01 \\
\hline \multicolumn{4}{|l|}{ Residence } \\
\hline Urban & 1441 & 1.00 & \\
\hline Rural & 1764 & 0.93 (0.8 to 1.1$)$ & 0.42 \\
\hline \multicolumn{4}{|l|}{ Education } \\
\hline Literate & 2044 & 1.00 & \\
\hline Illiterate & 1161 & $1.20(0.98$ to 1.5$)$ & 0.08 \\
\hline \multicolumn{4}{|l|}{ Occupation } \\
\hline Manual & 2070 & 1.00 & \\
\hline Non-manual & 1135 & $0.83(0.67$ to 1.0$)$ & 0.07 \\
\hline \multicolumn{4}{|l|}{ Diabetes mellitus } \\
\hline No & 2789 & 1.00 & \\
\hline Yes & 416 & 1.7 (1.3 to 2.1$)$ & $<0.001$ \\
\hline \multicolumn{4}{|l|}{ Hypertension } \\
\hline No & 1931 & & \\
\hline Yes & 1274 & 1.2 (0.97 to 1.4$)$ & 0.11 \\
\hline \multicolumn{4}{|l|}{ Smoking } \\
\hline No & 2348 & 1.00 & \\
\hline yes & 584 & 0.88 (0.64 to 1.2$)$ & 0.41 \\
\hline \multicolumn{4}{|l|}{ Alcohol consumption } \\
\hline No & 2313 & 1.00 & \\
\hline yes & 619 & $0.88(0.65$ to 1.2$)$ & 0.43 \\
\hline \multicolumn{4}{|l|}{ Smokeless tobacco use } \\
\hline No & 2467 & 1.00 & \\
\hline yes & 465 & $1.2(0.92$ to 1.5$)$ & 0.20 \\
\hline \multicolumn{4}{|l|}{ Laser peripheral iridotomy } \\
\hline Not done & 3015 & 1.00 & \\
\hline Done & 190 & 1.7 (1.3 to 2.4$)$ & $<0.001$ \\
\hline \multicolumn{4}{|l|}{ BMI } \\
\hline Normal & 1488 & 1.00 & \\
\hline Underweight & 514 & $1.0(0.83$ to 1.3$)$ & 0.36 \\
\hline Obese & 709 & 0.88 (0.69 to 1.1$)$ & 0.27 \\
\hline Overweight & 221 & $1.2(0.83$ to 1.7$)$ & 0.77 \\
\hline
\end{tabular}


Table 4 Baseline risk factors for different types of cataract progression

\begin{tabular}{|c|c|c|c|c|c|c|c|}
\hline \multirow[b]{2}{*}{ Baseline risk factors } & \multirow[b]{2}{*}{ No of subjects } & \multicolumn{2}{|l|}{ Nuclear cataract } & \multicolumn{2}{|l|}{ Cortical cataract } & \multicolumn{2}{|c|}{ Posterior subcapsular cataract } \\
\hline & & $\begin{array}{l}\text { Adjusted } \\
\text { OR }(95 \% \mathrm{Cl})\end{array}$ & $\mathrm{p}$ Value & $\begin{array}{l}\text { Adjusted } \\
\text { OR }(95 \% \mathrm{Cl})\end{array}$ & $\mathrm{p}$ Value & $\begin{array}{l}\text { Adjusted } \\
\text { OR }(95 \% \mathrm{Cl})\end{array}$ & $\mathrm{p}$ Value \\
\hline \multicolumn{8}{|l|}{ Age (years) } \\
\hline 40-49 & 1743 & 1.00 & & 1.00 & & 1.00 & \\
\hline $50-59$ & 915 & 2.80 (2.0 to 4.0$)$ & $<0.001$ & 1.8 (1.4 to 2.2$)$ & $<0.001$ & $2.7(1.8$ to 4.1$)$ & $<0.001$ \\
\hline $60-69$ & 406 & 4.56 (3.1 to 6.7$)$ & $<0.001$ & 2.1 (1.6 to 2.8 ) & $<0.001$ & 4.7 (3.0 to 7.4$)$ & $<0.001$ \\
\hline $70+$ & 88 & 4.97 (2.6 to 9.7$)$ & $<0.001$ & 2.1 (1.2 to 3.6$)$ & $<0.001$ & $6.6(3.3$ to 13.4$)$ & $<0.001$ \\
\hline \multicolumn{8}{|l|}{ Gender } \\
\hline Male & 1379 & 1.00 & & 1.00 & & 1.00 & \\
\hline Female & 1773 & $1.4(1.1$ to 1.9$)$ & 0.02 & $1.3(1.0$ to 1.6$)$ & 0.02 & $1.0(0.74$ to 1.4$)$ & 0.88 \\
\hline \multicolumn{8}{|l|}{ Residence } \\
\hline Urban & 1413 & 1.00 & & 1.00 & & 1.00 & \\
\hline Rural & 1739 & 0.94 (1.3 to 0.7$)$ & 0.71 & 0.93 (1.1 to 0.76$)$ & 0.46 & 1.19 (1.7 to 0.8$)$ & 0.32 \\
\hline \multicolumn{8}{|c|}{ Laser peripheral iridotomy } \\
\hline Not done & 2967 & 1.00 & & 1.00 & & 1.00 & \\
\hline Done & 185 & $1.5(0.94$ to 2.5$)$ & 0.09 & 1.6 (1.1 to 2.3$)$ & 0.007 & $1.6(0.93$ to 2.8$)$ & 0.09 \\
\hline \multicolumn{8}{|l|}{ Diabetes } \\
\hline Mellitus & 2748 & 1.00 & & 1.00 & & 1.00 & \\
\hline No:yes & 404 & 2.1 (1.5 to 2.9 ) & $<0.001$ & 1.5 (1.2 to 2.0$)$ & 0.003 & $1.5(0.93$ to 2.3$)$ & 0.10 \\
\hline
\end{tabular}

PACS, were significantly older $(p<0.001)$, female $(p=0.008)$, urban residents $(p=0.001)$ and patients with hypertension $(\mathrm{p}<0.001)$. Cataract progression as we defined was seen in $38.9 \%$ (95\% CI $32.0 \%$ to $45.9 \%$ ) of eyes among those who had undergone LPI at baseline compared with 23.1\% (95\% CI $21.6 \%$ to $24.6 \%)$ of eyes that had no intervention $(\mathrm{p}<0.0001)$.

During the 6-year follow-up, 53 subjects had undergone cataract surgery. Figure 2 provides the cataract surgery rates between two groups. Table 2 provides the data on progression of cataract. The cataract progression rates as per our definition were significantly higher in eyes that had undergone LPI for PACS. Figure 3 shows the progression of cataract in different age groups. While the progression of cataract increased with increasing age, rates were higher in the LPI group for cortical cataract and any cataract. On logistic regression (table 3), the baseline risk factors for progression of cataract for the entire study population were age $(p<0.001)$, female gender $(p=0.01)$, diabetes $(p<0.001)$ and LPI $(p<0.001)$. The odds for progression of cataract for the LPI for PACS group were 1.7 (95\% CI 1.3 to 2.4). These four risk factors were further analysed for risk of progression for types of cataract (table 4). Diabetes and female gender were significant risk factors for nuclear and cortical cataract progression, whereas peripheral iridotomy was a risk factor only for cortical cataract (OR 1.6, 95\% CI 1.1 to $2.3, \mathrm{p}=0.007)$.

\section{DISCUSSION}

Traditionally prophylactic peripheral iridotomy is recommended for all PAC disease. In the era of surgical iridectomy, provocative tests were advocated for asymptomatic narrow angles for decision-making. With the introduction of laser, the practice has changed. The indications for LPI changed from acute attacks and positive provocative tests, to all anatomically narrow angles based on clinical examination without much dependence on provocative tests. This has been controversial especially in Asia since not all people with PACS will progress to PAC or PACG. ${ }^{11}$ In the absence of strong supportive evidence of its utility in preventing disease progression, LPI is currently recommended, in
Asia, for the perceived 'highest risk' groups for a large population with PACS due to limited healthcare resources. ${ }^{8-10}$

Studies have evaluated the risk of cataract formation following LPI. The initial studies were based on visual acuity measurements, where a decrease in visual acuity was attributed to the cataract formation. With a mean follow-up of 1.8 years and 5 years, there was some visual loss attributable to cataract formation and this was comparable to the cataract formation following surgical iridectomy for angle closure. ${ }^{14}{ }^{15}$ In another report, with a short-term follow-up of 6 months, the visual loss attributable to cataract formation was $2.1 \%{ }^{16}$ Lim et al ${ }^{10}$ were the first to prospectively evaluate the changes in the lens opacity after LPI in fellow eyes of subjects with acute PAC. Using the LOCS III classification system they reported significant progression in $23.3 \%$ of eyes (95\% CI $16.9 \%$ to $29.7 \%$ ). In their series, progression of PSC occurred more often than the nuclear or cortical cataract. In the current study, nuclear cataract, cortical cataract, PSC and any type of cataract with cataract surgery was significantly more in the group that had undergone LPI for PACS in comparison to the rest of the study population. On logistic regression, the baseline risk factors for cataract progression were female gender, diabetes and LPI. The first two conditions were risk factors for the progression of all three types of cataract whereas LPI was a risk factor only for cortical cataract progression. In contrast to these reports, in a study from Mongolia Yip et al, ${ }^{17}$ reported no significant difference in cataract progression using the LOCS III classification system, between the LPI group and the rest of the study population, 6 years after the LPI for PAC. Even though the available information is scanty, it appears from some studies that LPI can have an effect on the cataract progression. While other factors such as postiridotomy inflammation and the use of topical steroids could potentially increase the risk of cataract formation we believe the short course (four times a day for a week) is unlikely to be contributory. All lasers were performed at the same centre by one of the study ophthalmologists. Since PACS can be related to increased lens thickness secondary to increasing nuclear sclerosis, the resultant index myopia could contribute to earlier cataract surgery in these eyes. The rates of cataract surgery $(2.6 \%$ in 
the LPI group and $1.5 \%$ in the rest) were small and not statistically significant $(p=0.45)$ for both groups and the very early nuclear sclerosis, which is usually associated with significant refractive change, were excluded in both groups by definition.

There are an estimated 21 million persons with PACS in India. ${ }^{18}$ It may not be possible or essential to treat all people with PACS with LPI. It is not possible because of constraints in the resources and not needed because of the very low risk of progression. $^{6} 7$ In the initial report on the natural history of PACS, angle width of treated eyes increased following LPI and remained stable for 6 months, then showed significant decrease in 18 months. At the present point of time LPI has not shown any great advantage over observation for PACS. ${ }^{19}$ The Asia Pacific Guidelines for glaucoma do not recommend LPI for all PACS mainly because the natural history of PACS is not well known. ${ }^{20}$ For the Indian population, the leading cause of blindness is cataract and there are limited healthcare and financial resources to tackle cataract blindness. ${ }^{21-23}$ Any potential increase in the cataract burden (such as following LPI) can have an adverse effect on the blindness eradication programme. For the present our findings strengthen the rationale behind continuing to follow the Asia Pacific Guidelines for glaucoma-LPI for select cases of PACS, all cases of PAC and PACG.

In conclusion, in the present study, we report significant cataract progression in 6 years following LPI for PACS. Our findings contribute towards therapeutic decision-making for asymptomatic and slowly progressive PACS. However, one should not forget the beneficial role of LPI for PAC, PACG and in preventing acute PAC.

Contributors Substantial contributions to conception and design, acquisition of data, or analysis and interpretation of data: LV, RG, RA and MP. Statistical analysis: RG and RA. Drafting the article or revising it critically for important intellectual content: LV, RG, RA and MP. Final approval of the version to be published: LV and RG.

Funding This study was partially funded by Chennai Willingdon Corporate Foundation, Chennai.

Competing interests LV and RG have received funds for lectures from Allergan and LV from Pfizer.

Patient consent Obtained.

Ethics approval Vision Research Foundation.

Provenance and peer review Not commissioned; externally peer reviewed.

\section{REFERENCES}

1 Quigley HA, Broman AT. The number of people with glaucoma worldwide in 2010 and 2020. Br J Ophthalmol 2006;90:262-7.
2 Tham YC, Li X, Wong TY, et al. Global prevalence of glaucoma and projections of glaucoma burden through 2040: a systematic review and meta-analysis. Ophthalmology 2014;121:2081-90.

3 Vijaya L, George R, Arvind $\mathrm{H}$, et al. Prevalence of angle-closure disease in a rural southern Indian population. Arch Ophthalmol 2006;124:403-9.

4 Vijaya L, George R, Arvind $\mathrm{H}$, et al. Prevalence of primary angle-closure disease in an urban south Indian population and comparison with a rural population. The Chennai Glaucoma Study. Ophthalmology 2008;115:655-60.e1.

5 Vijaya L, Asokan R, Panday M, et al. Six-Year Incidence of Angle-Closure Disease in a South Indian Population: The Chennai Eye Disease Incidence Study. Am J Ophthalmol 2013;156:1308-15.

6 Thomas R, George R, Parikh R, et al. Five year risk of progression of primary angle closure suspects to primary angle closure: a population based study. $\mathrm{Br}$ J Ophthalmol 2003;87:450-4.

7 Thomas R, Parikh R, Muliyil J, et al. Five-year risk of progression of primary angle closure to primary angle closure glaucoma: a population-based study. Acta Ophthalmol Scand 2003;81:480-5.

8 Spaeth GL, Idowu O, Seligsohn A, et al. The effects of iridotomy size and position on symptoms following laser peripheral iridotomy. I Glaucoma 2005;14:364-7.

9 Kumar RS, Baskaran M, Friedman DS, et al. Effect of prophylactic laser iridotomy on corneal endothelial cell density over 3 years in primary angle closure suspects. $\mathrm{Br}$ J Ophthalmol 2013;97:258-61.

10 Lim LS, Hussain R, Gazzard G, et al. Cataract progression after prophylactic laser peripheral iridotomy. Potential implications for the prevention of glaucoma blindness. Ophhalmology 2005;112:1355-9.

11 Ronnie G, Ve RS, Velumuri L, et al. Importance of population-based studies in clinical practice. Indian J Ophthalmol 2011;59:11-18.

12 Arvind H, Paul PG, Raju P, et al. Methods and design of the Chennai Glaucoma Study. Ophthalmic Epidemiol 2003;10:337-48.

13 Foster PJ, Buhrmann R, Quigley HA, et al. The definition and classification of glaucoma in prevalence surveys. Br I Ophthalmol 2002;86:238-42.

14 Quigley HA. Long-term follow-up of laser iridotomy. Ophthalmology 1981;88:218-24.

15 Robin AL, Pollack IP. Argon laser peripheral iridotomies in the treatment of primary angle closure glaucoma: long-term follow-up. Arch Ophthalmol 1982;100:919-23

16 Hsiao CH, Hsu CT, Shen SC, et al. Mid-term follow-up of Nd:YAG laser iridotomy in Asian eyes. Ophthalmic Surg Laser Imaging 2003:34:291-8.

17 Yip JL, Nolan WP, Gilbert CE, et al. Prophylactic laser peripheral iridotomy and cataract progression. Eye (Lond) 2010;24:1127-35.

18 George R, Ve RS, Vijaya L. Glaucoma in India: estimated burden of disease. J Glaucoma 2010;19:391-7.

19 Jiang Y, Chang DS, Zhu H, et al. Longitudinal changes of angle configuration in primary angle-closure suspects: the Zhongshan Angle-Closure Prevention Trial. Ophthalmology 2014;121:1699-705.

20 South East Asia Glaucoma Interest Group. Asia pacific glaucoma guidelines. 2nd edn. Sydney: South East Asia Glaucoma Interest Group, 2008:23-4.

21 Vijaya L, George R, Arvind $\mathrm{H}$, et al. Prevalence and causes of blindness in the rural population of the Chennai Glaucoma Study. Br I Ophthalmol 2006;90:407-10.

22 Vijaya L, George R, Asokan R, et al. Prevalence and causes of low vision and blindness in an urban population: The Chennai Glaucoma Study. Indian J Ophthalmol 2014;62:477-81.

23 Vijaya $L$, Asokan R, Panday $M$, et al. Baseline risk factors for incidence of blindness in a south Indian population: the Chennai Eye Disease Incidence Study. Invest Ophthalmol Vis Sci 2014;55:5545-50. 